\title{
Five challenges to reconcile agricultural land-use and forest ecosystem services in Southeast Asia
}

Article in Conservation Biology · May 2016

DOI: $10.1111 /$ cobi.12786

CITATION

1

8 authors, including:

L Roman Carrasco

National University of Singapore

53 PUBLICATIONS 380 CITATIONS

SEE PROFILE

Amy Ickowitz

Consultative Group on International Agricult...

41 PUBLICATIONS 710 CITATIONS

SEE PROFILE
READS

149
Sarah Papworth

Royal Holloway, University of London

22 PUBLICATIONS 246 CITATIONS

SEE PROFILE

Kelvin S.-H. Peh

University of Southampton

72 PUBLICATIONS $\mathbf{1 , 5 2 8}$ CITATIONS

SEE PROFILE 
This is the preprint version of the article and not the final accepted version. The final accepted version can be accessed from: http://onlinelibrary.wiley.com/doi/10.1111/cobi.12786/pdf

Please cite it as: Carrasco, L. R., S. K. Papworth, J. Reed, W. S. Symes, A. Ickowitz, T. Clements, K. S. H. Peh, and T. Sunderland. 2016. Five challenges to reconcile agricultural land use and forest ecosystem services in Southeast Asia. Conservation Biology. doi: 10.1111/cobi.12786.

\section{Five challenges to reconcile agricultural land use and forest ecosystem services in Southeast Asia}

L.R. Carrasco 1,* , S.K. Papworth ${ }^{1}$, J. Reed ${ }^{2}$, W.S. Symes ${ }^{1}$, A. Ickowitz ${ }^{2}$, T. Clements ${ }^{3,4}$, K.S-H. Peh ${ }^{5,3}$, T. Sunderland ${ }^{2,6}$

${ }^{1}$ Department of Biological Sciences, National University of Singapore, 14 Science Drive 4, Singapore 117543, Republic of Singapore; ${ }^{2}$ Center for International Forestry Research, Bogor 16000 , Indonesia; ${ }^{3}$ Department of Zoology, University of Cambridge, Downing Street, Cambridge CB2 3EJ, U.K; ${ }^{4}$ Wildlife Conservation Society, 2300 Southern Boulevard, Bronx, NY 10460, U.S.A.; ${ }^{5}$ Centre for Biological Sciences, University of Southampton, University Road, Southampton SO17 1BJ, U.K.; ${ }^{6}$ Center for Tropical Environmental and Sustainability Science, School of Earth and Environmental Sciences, James Cook University, Cairns, Queensland, 4870, Australia*email dbsctlr@nus.edu.sg

\section{Abstract}

Southeast Asia possesses the highest rates of tropical deforestation globally and exceptional levels of species richness and endemism. Many countries in the region are also recognized for their food insecurity and poverty, making the reconciliation of agricultural production and forest conservation a particular priority. This reconciliation requires recognition of the trade-offs between competing land-use values and the subsequent incorporation of this information into policy making. To date, such reconciliation has been relatively unsuccessful across much of Southeast Asia.

We propose an ecosystem services (ES) value internalization framework which identifies key challenges for such reconciliation: (i) lack of accessible ES valuation techniques; (ii) limited knowledge of the links between forests, food security and well-being; (iii) weak demand and political will for the integration of ES in economic activities and environmental regulation; (iii) disconnection between decision-makers and ES valuation; and (v) lack of transparent discussion platforms where stakeholders can work towards consensus on negotiated land-use management decisions.

Key research priorities to overcome these challenges are developing easy to use ES valuation techniques, quantifying links between forests and well-being that go beyond economic values, understanding factors that prevent the incorporation of ES into markets, regulations and environmental certification schemes, understanding how to integrate ES valuation into policy making processes, and how to reduce corruption and power plays in land-use planning processes.

Key words: forest economics; landscape conservation planning; wellbeing; payment for ecosystem services. 
Land conversion to agricultural use is the leading global cause of biodiversity loss and a major driver of deforestation in Southeast Asia (Sodhi et al. 2004), a region that experiences greater deforestation rates than other tropical regions (Margono et al. 2014). This rapid habitat loss is alarming because of Southeast Asia's (SE Asia) high species richness and endemism, including four of the twenty most important global biodiversity hotspots: Indo-Burma, Sundaland, Wallacea and The Philippines (Myers et al. 2000) (Fig. 1).

Deforestation in SE Asia is driven by economic forces that respond to increasing demand for agricultural products, timber, fiber and mining (Abood et al. 2014). Due to rapid population growth, poverty, weak governance, and lack of conservation expertise and resources, reconciling conflicts between economic development and the environment remains a leading challenge for policy and practice in SE Asia (Sodhi et al. 2004) (Fig. 2). Therefore, there is a need for options that decouple increasing demand for agricultural land and negative impacts on tropical biodiversity. Economic options include land-use planning that recognizes the trade-offs between forest ecosystem services (ES) and agriculture (e.g. Runting et al. 2015). Related alternatives to reconcile economic development and biodiversity conservation are those which limit the demand of the products with the highest environmental footprint (e.g. oil palm, cattle production) (Nghiem \& Carrasco 2016); changing product sources and consumer consumption patterns through certification schemes; and alternative diets with lower environmental footprints in highincome importing countries (Bateman et al. 2015; Tilman \& Clark 2014).

Economic returns of agricultural conversion often outweigh the economic value of ES provided by standing forests if ES are not recognized by both markets and decision-makers, potentially leading to unsustainable land-use decisions (Balmford et al. 2002) (Fig. 2). A market failure (inefficient allocation of resources) occurs then when forests are converted to agriculture even if the value of ES is greater than the value of agriculture. To correct the market failure it is necessary as a first step to integrate the environmental costs of forest conversion into decision making, which requires valuation of ES. In addition, because tropical forests in SE Asia provide a wide range of goods and services that are highly valued by human populations in the region (Abram et al. 2014), it is important to consider the value of ES provided by forests, and compare these with agricultural benefits when planning the conversion of forests into agriculture (Bateman et al. 2015; Runting et al. 2015) (Fig. 2).

The practicalities of incorporating forest ES values, food security and well-being considerations into land-use planning pose significant challenges in SE Asia. Identifying these challenges is a first step towards reconciling forest ES and agriculture. The objectives of this essay are: (i) to develop an ES value internalization framework to identify the main challenges for reconciling agricultural land-use and forest ES in SE Asia; and (ii) to identify key research priorities to overcome these challenges.

\section{An ES value internalization framework to identify challenges for the reconciliation of agriculture and forest ES}


Potential emerging challenges were identified at the symposium "Reconciliation of biodiversity conservation, ecosystem service provision and food security in the tropics" at the Society of Conservation Biology Asia Chapter held in Malacca (Malaysia) in August 2014. The symposium organizers (L.R.C. and T.S.) identified and selected experts working on biodiversity conservation, ES valuation, food security, and conservation interventions (e.g. payment for ecosystem services, PES) in SE Asia. The symposium participants were asked to identify the main challenges faced in their areas of research with respect to the reconciliation of forest ES and agricultural production in SE Asia. To identify and select the main ongoing challenges that emerged from the symposium we developed a forest ES internalization framework (Fig. 2, Table 1, (Cowling et al. 2008)). We developed a valuation-knowledge-demand-engagement-consensus framework that describes the factors and processes (where their lack or malfunctioning represent challenges) necessary to internalize ES into policy for application on the ground (Fig. 2, Table 1). Internalization of ES into policy is contingent on three necessary conditions: (i) adequate tools to value ES; (ii) adequate understanding of the links between forests, food security and people's well-being; and (iii) sufficient demand for ES integration in economic activities, and political will to integrate ES in regulatory frameworks. Once these conditions are met, the further two key processes are: (iv) integration of ES valuation within policy making processes; and (v) consensus building with all stakeholders to derive policy influence and change.

Challenge 1. Do we have the right tools to value ES in SE Asia?

98

99

100

101

102

103

104

105

106

107

108

109

110

111

112

113

114

115

116

117

118

119

120

121

122
Over the last few decades, ES academic studies applied to forest management have increased dramatically. Their inclusion in planning and decision-making processes is, however, very low, highlighting a distinct gap between theory and actual implementation. There remain a number of data and technical barriers to measuring ES values accurately and cost-effectively, particularly in Southeast Asia where environmental research has lagged behind other regions (Sodhi et al. 2004). For example, existing software packages for assessing ES, such as 'Integrated Valuation of ES and Trade-offs' (InVest; http://www.naturalcapitalproject.org/InVEST.html) require advanced modelling and geographic information systems (GIS) skills. This may hinder the inclusion of ES as part of regular planning and policy-making procedures in SE Asia, due to a general lack of expertise in these areas. Hence, a SE Asian ES framework should be underpinned with practical approaches that support and build on current planning capacity in SE Asia. One possibility is the application of these tools by external agencies with funding from outside SE Asia or using benefit transfer statistical approaches (Carrasco et al. 2014). Although these approaches offer valuable spatial information, they do not empower local people to carry out analyses and develop ownership, which is key for long-term success (Ruckelshaus et al. 2013).

Other alternatives are simple rapid assessment protocols that can be locally applied. For instance, the 'Toolkit for Ecosystem Service Site-based Assessment' (TESSA; http://tessa.tools/) can help understand the impact of actual and potential ES changes at individual sites (Peh et al. 2013). These fit-for-purpose toolkits-which provide guidance on how to identify important ES and a series of standardized protocols for measuring them-focus on site-scale assessments, and so are relevant for local decision-making. These characteristics make protocols such as TESSA highly relevant in SE Asia, where land-use decisions occur rapidly, and resources (budget, manpower, capacity) are limited (Sodhi et al. 2004).

Measuring the economic benefits from forests, however, is insufficient for effective forest management. We also need to quantify the linkages between ES, well-being and development 
opportunities. These challenges can be potentially addressed by integrating a suite of complex models (e.g. ARIES, InVest), or through benefit transfer approaches which use robust data from toolkits like TESSA. This integration, which should be a future research priority (Table 2), could capture dynamic stocks, flows of ES and beneficiaries to identify diverse development alternatives at the local level.

\section{Challenge 2. Poor knowledge of the link between forests ES, food security and well-being}

Efforts to value ES can focus narrowly on economic values (e.g., in PES). A restricted approach might, for example, seek to reconcile agricultural production and forest ES by identifying scenarios that yield greatest profits. This can overlook diverse social equity considerations that shape decision-making (McDermott et al. 2013), as well as a diversity of cultural and social values that fail to make it into policy (Chan et al. 2012). These issues are particularly salient for decision-making across much of SE Asia where there are concerns with food security, poverty alleviation, indigenous rights and, from a broader perspective, human well-being.

Because economic valuation of ES fails to incorporate the relative importance of ES to people and societal levels of dependence on ES, ES valuation that considers well-being instead of only economic values is increasingly proposed (Stiglitz et al. 2010). The links between forest ES and well-being - which includes material needs, social relations, health, security and freedom of choice - are however difficult to monetize or even quantify, leading to large knowledge, and thus implementation gaps (Ruckelshaus et al. 2013). Nevertheless, characterizing these poorly understood links is fundamental for conservation interventions such as PES in tropical lowincome regions where culture and community structure play important roles (Milner-Gulland et al. 2014). One key aspect of well-being is health, which is intimately linked to provisioning ES that fulfil basic nutritional needs. Increasing efforts to characterize the role of forests for food security and health can capture important links between forest ES and well-being through food security (Ickowitz et al. 2014).

Food security means ensuring people consume enough food and have access to diets that meet their nutritional requirements. Globally, micronutrient deficiencies are estimated to cause $12 \%$ of deaths in children under five (Black et al. 2003). The micronutrients most commonly missing from diets in Southeast Asia are iron, vitamin A, iodine, and zinc (FAO 1997). Typically, forest foods are rich sources of micronutrients; animal source foods are high in bioavailable iron and zinc, and forest fruits and vegetables can be rich sources of vitamin A and iron (Powell et al. 2015).

These micronutrient-rich foods can be collected from 'natural' wild forests, but the crop and species diversity of some types of agriculture practiced in forested landscapes, particularly swidden agriculture and agroforestry (where staple crops are intercropped with legumes and also managed for hunting), can also result in high quality diverse diets (Padoch \& Sunderland 2014).

Although the relationship between forests and nutrition is gaining increasing attention (Sunderland et al. 2013), empirical evidence documenting these contributions remains scarce. In SE Asia there has been very little quantitative nutrition research investigating such relationships (Powell et al. 2015). To our knowledge, there have been only five studies, and only one that 
reports nutrient level information. This single study finds wild foods make an important contribution to vitamin A intake in the Tiruray region of the Philippines (Schlegel \& Guthrie 1973). Other studies from Papua New Guinea (Dwyer 1985), Indonesia (Colfer \& Soedjito 1996), Timor-Leste (Erskine et al. 2015) and Vietnam (Ogle et al. 2001) all document extensive use of wild products. However, sample sizes are small and research methods vary considerably. Since many tropical forests are cleared for agriculture, it is imperative to understand the true costs of clearing forests for peoples' diets and compare this with other changes in well-being. After forest landscapes are displaced by agriculture, agriculture may increase calories from staple crops, but at the potential loss of nutritious foods from parts of the landscape. To investigate this, more rigorous nutrition research with substantial sample sizes, clear selection criteria for study sites, and attention to ecological context is necessary (Table 2).

As exemplified with food security and nutrition, our current limited understanding of the links between forest ES, food security and well-being hinders the evaluation of trade-offs between agriculture and forest ES. Further research quantifying those links is thus necessary to support ES valuation from a broader well-being perspective (Table 2, Fig. 2). Such research would need to collect well-being and environmental information, together with data on potential confounders, before and after forest conversion. Matched pairs or the use of spatial statistical models, combined with household surveys can help overcome these knowledge challenges.

\section{Challenge 3. Weak demand for ES integration in economic activities and regulatory frameworks}

ES can be internalized into economic activities, inter alia, through international and local ES markets, environmental certification schemes, corporate social responsibility, environmental impact assessment (EIA) and direct government regulation (e.g. taxation and subsidies).

Developing strong and self-sustaining local and international ES deals remains however a fundamental challenge. The two main existing ES sets of contracts in SE Asia are in carbon and water. Carbon markets have greater potential for attracting international buyers due to the links between tropical deforestation and climate change. The potential of carbon markets has not been fully realized however, as political issues prevented forest conservation projects from joining the Kyoto protocol as clean development mechanisms. Nevertheless, the United Nations Programme on Reducing Emissions from Deforestation and Forest Degradation (REDD+) has been slowly growing, and the central role of forests on the 21 Conference of the Parties Paris agreement in 2015 may signify a takeoff for REDD+.

Water contracts attract mostly local buyers in the form of hydropower companies, e.g. $\$ 50 \mathrm{M}$ were spent in 2013 (Forest Trends 2015), chiefly associated with watershed services in Asia. The number of watershed programs has however slowed since 2009 (Forest Trends 2015), making the identification of ways to foster ES contract creation research priorities (Table 2). Environmental certification schemes such as High Conservation Value Area and Certified Sustainable Palm Oil (CSPO) also offer potential to integrate forest ES into certification of agricultural products in SE Asia. The certification of forest ES could internalize the value of ES, but suffers from the noted problem of limited demand which, in this case, is exacerbated with the high transactions and monitoring costs of certification of forest ES (Meijaard et al. 2014). 
EIA is another way to incorporate ES into decision making through regulatory frameworks. Although EIAs are increasingly carried out in SE Asian countries, the quality of the standard, its implementation in the field and the interpretation afterwards are many times not adequate. In addition, in most cases, ES and biodiversity are not part of the EIAs or are poorly enforced (Phillips et al. 2009). Another alternative to incorporate ES is through direct government regulation through command-and-control policies (e.g. via sanctions). Although this is very rare in SE Asia, the smoke pollution episodes ("haze") due to forest fires in Indonesia have led to environmental laws aimed to sanction responsible agri-business companies (Lee et al. 2016). The very low use of regulation to incorporate ES denotes, however, a lack of political will to make ES an integral part of regulatory frameworks in the region. Future research should thus focus on identifying ways to scaling-up forest ES certification and enhancing the integration of ES valuation in EIAs (Table 2).

\section{Challenge 4. Failed integration of ES valuation within policy-making}

While ES valuation is widely discussed as helpful for informing policy, there is limited documented evidence of its actual operationalization (Laurans et al. 2013; Ruckelshaus et al. 2013). This can be attributed to numerous technical limitations, including low engagement between environmental economists and policy makers, and a lack of accessible decision-support platforms. Equally, however, ES valuation is part of a process-based approach to decisionmaking (Laurans \& Mermet 2014). This views valuation as part of broader governance processes to ensure ES frameworks are meaningfully operationalized to inform policy. This broadened line of enquiry recognizes that valuation should engage diverse stakeholders (Laurans et al. 2013). How valuation data are created and used, and whose interests are represented in decision-making processes should be actively considered (Phelps et al. 2014). This includes, for example, how and whether formal processes recognize the diverse uses and values of ES for local actors.

As valuation initiatives to inform decision-making emerge across SE Asia, they should be part of broader decision-making processes. ES valuation should not be restricted to environmental benefits and costs, but consider also social aspects and the well-being of local people. The divide between the theory of environmental economics and the actual application of ES valuation and how this will influence land-use on-the-ground must be carefully studied if forest ES and agricultural production are to be reconciled (Table 2).

\section{Challenge 5. Lack of strong consensus building platforms to reconcile competing land-uses}

Bringing together policy makers and stakeholders can facilitate consensus for land management. One potential framework to reconcile competing land uses in SE Asia are "landscape approaches" which improve understanding and recognize interconnections between different land uses and the stakeholders who derive benefits from them (Sayer et al. 2013). Such landscape approaches also aim to reconcile competing land uses and achieve conservation, production and socio-economic outcomes (Sayer et al. 2013).

Despite the utility of landscape approaches for both sustainable agriculture and forest ES conservation, they should not be seen as prescriptive approaches to spatial planning. Published 
principles for landscape approaches (Sayer et al. 2013) are not a set of boxes to be ticked in search for an agreed spatial plan, but a framework of approaches which practitioners can draw on to solve real problems on the ground. There are fundamental difficulties in identifying and agreeing on metrics to measure progress in solving "wicked" problems (Game et al. 2014; Sayer et al. 2013). If opinions differ on optimal solutions then no single metric can measure, or even define, "success", particularly when trade-offs are the norm, as in SE Asia. The application of landscape principles might eventually lead to a spatial plan accepted by stakeholders, but landscapes are constantly changing under the influence of multiple drivers, and end points in the form of long-term plans appear to be the exception rather than the rule.

Much of the theory and practice of landscape approaches is underpinned by the assumption that facilitation and negotiation will eventually allow consensus. However, in reality there are often entrenched views, conflicts of interest and power plays. Conflict between agriculture, conservation and other competing land uses is often the subject of strongly contested activism with highly polarized positions (Sunderland et al. 2008). Advocates of landscape approaches sometimes appear to assume that conflict can be avoided by resolving these fundamental differences. In reality, any intervention will bring 'winners' and 'losers' in any rural community - including 'traditional societies' living in or on the edge of forest habitats - and will be heterogeneous and characterized by various internal conflicts. Ignoring this heterogeneity and these internal conflicts may weaken local communities against the influence of new powerful stakeholders in SE Asia such as logging, agro-businesses and mining companies, challenging the internalization of ES.

With increasing anthropogenic and biophysical pressures on forest ES across many landscapes in SE Asia, choices have to be made about what is desirable and how landscapes should be managed. Management regimes can optimize trade-offs and synergies among different outcomes, but there are always likely to be some trade-offs and opportunity costs (Leader-Williams et al. 2010). Bearing in mind that it may be impossible to reach consensus despite negotiation and facilitation, future research needs to focus on understanding the negotiation and institutional dynamics that hinder the adoption of sustainable strategies (Table 2).

\section{Discussion}

Through an ES value internalization framework, we have identified five main challenges to reconcile forest ES and agricultural production in SE Asia (Table 1, Fig. 2). Technical challenges arise because most methods to estimate the value of ES require detailed data or expertise that may not be available (Table 1, challenge 1). Even if economic value maps are produced exogenously, rapidly changing conditions and the fact that ES values change in space and time (Renard et al. 2015) mean policy makers need tools to evaluate and adapt to the dynamic nature of local environments. In addition, valuation tools would ideally empower local people to participate in the estimation of benefits provided by forests and agriculture (Ruckelshaus et al. 2013). Although considering the temporal and spatial dimensions of ES and the heterogeneity among local communities would be ideal, in reality, however, a trade-off exists between the level of detail that policies can attain and how practical and implementable these policies are. This trade-off would be determined by the knowledge of the socio-ecological system where benefits from forests versus agriculture occur and how amenable it is to value the ES dynamically and 
spatially. Translating this knowledge into policies would thus require a balance between capturing the realities of the system and the practicality and simplicity of the policies.

Even though valuation analyses that reveal the environmental costs of forest conversion are necessary to reconcile forest ES and agriculture, they are only the first step. Valuation alone is unlikely to lead to change as it needs to be further integrated into decision-making through the engagement of environmental economists with policy making processes. Such engagement between environmental economists and policy makers seems, however, to be low, leading to scarce application of ES approaches that lead to improved outcomes for ES and well-being (Ruckelshaus et al. 2013). There is thus a need to create platforms where environmental economists can interact with policy makers in an iterative science-policy process (Table 1, challenge 4). This may even require reforming institutions and changing practices to consider society's long-term goals (Guerry et al. 2015). This lack of engagement with policy makers echoes the low inclusion of ES in regulatory frameworks and political will to enforce environmental protection in processes such as EIA. For instance, although EIAs in Indonesia are compulsory prior to the establishment of plantations on peatlands, the carbon emissions and loss of ES which result from conversion have very little weight over economic development considerations (Lee et al. 2016). Companies typically pay independent consultants to get the desired result from the EIA, making it a mere formality (McCarthy \& Zen 2010). Alternatively, to avoid conflicts of interests, payments for EIAs could be funded by the government or international agencies. Voluntary alternatives such as international and local contracts of ES, voluntary adoption of zero deforestation through corporate social responsibility and forest ES certification, though promising, suffer, on the other hand, from weak demand for ES (Meijaard et al. 2014). Given this situation, research identifying ways to enhance demand and political will towards ES should be a priority (Table 2).

Internalization of ES needs to consider the multiple dimensions of ES on human well-being, beyond economic values (Stiglitz et al. 2010), i.e. the social and cultural implications of land use allocations, and adoption of well-being and food security as outcomes to compare against agricultural benefits. We know little, however, about these links. For instance, because most studies have focused on income from non-timber forest products, little is known on how forests provide essential nutrients (Ickowitz et al. 2014). Expanding our knowledge about the relationship between local communities' well-being and forest needs to be executed before forest ES can be integrated in trade-off analyses (Table 1, challenge 2 and Fig. 2). This knowledge should be acquired through solid data-driven research where all the plausible development options and their well-being implications are considered for local stakeholders. Such research should evaluate the economic realities and livelihoods of people living in and around forests and the availability of alternative livelihoods (and how to provide them) need to be taken into account. Access to health systems, education, cultural preferences and general well-being will thus be needed to complement the economic valuation of ES and agricultural outputs. Who benefits, who loses and the social implications for, for instance, indigenous communities, need to be part of ES valuation in SE Asia if it is to effectively engage policy makers and society at large.

Although the importance of forests for poor people in low-income countries is clear (Foli et al. 2014; Nasi et al. 2008), deforestation brought about by large agribusiness companies can provide opportunities in the form of labor, schooling and health services. But they also create conflict by 
competing with local land ownership rights. Development that empowers local people to own and manage their own agricultural land, while offering alternative sources of income (e.g. ecotourism, PES), and determining the role of the forest to complement their income, may represent a more effective way to alleviate poverty than large agribusiness land conversion (indeed this form of development was preferred by local people in Borneo (Abram et al. 2014). Future research would thus need to evaluate the well-being implications of land conversion by large companies versus other forms of development with different levels of forest conservation (Table 2).

Building on solid valuation methods and land-use socio-ecological systems knowledge, consensus between the key stakeholders involved in land-use decisions, e.g. using landscape approaches, should be attempted through facilitation and negotiation, even if consensus is impossible to reach in many instances. The reality however is that weak governance and inequitable power relations prevail above negotiation and consensus (Table 1, challenge 5). These inequitable power relationships explain also the gap between economic theory and failed ES policy implementation. This is because the economic value of ES is often not received by the providers of the services. Elite capture of PES program benefits has extensively been document in SE Asian countries (Howson \& Kindon 2015; To et al. 2012). For instance, in the carbon finance project of Sungai Lamandau in Indonesia, the ability to secure benefits was obstructed by government licensing and a function of social relationships and access to local markets (Howson \& Kindon 2015). Similarly, an analysis of PES projects in Vietnam showed how monopolization of access to forestland and existing state forestry prevented the poor from receiving benefits (To et al. 2012). Adequate land tenure regimes, mapping of ES providers and allowing different actors to negotiate on a level playing field could contribute to mitigate elite capture and consensus to be translated into policies.

Given the challenges identified, research efforts that could produce the greatest contributions to ES internalization in SE Asia can be summed up as: developing easy to use dynamic ES valuation tools that can capture the relationship between forest ES and well-being; identifying ways to foster local and global ES markets, contracts and the incorporation of ES in properly enforced EIA; understanding factors hindering the inclusion of ES into policy making; and strategies to reduce factors that facilitate power plays and corruption in platforms for negotiation among key stakeholders (Table 2). Research focusing on these challenges and how they interrelate would facilitate the reconciliation of agriculture and forests ES in SE Asia, a region where imperative economic development goals overlap with extraordinary biodiversity riches. 


\section{References}

Abood, S. A., J. S. H. Lee, Z. Burivalova, J. Garcia-Ulloa, and L. P. Koh. 2014. Relative contributions of the logging, fiber, oil palm, and mining industries to forest loss in Indonesia. Conservation Letters.

Abram, N. K., E. Meijaard, M. Ancrenaz, R. K. Runting, J. A. Wells, D. Gaveau, A.-S. Pellier, and K. Mengersen. 2014. Spatially explicit perceptions of ecosystem services and land cover change in forested regions of Borneo. Ecosystem Services 7:116-127.

Balmford, A., A. Bruner, P. Cooper, R. Costanza, S. Farber, R. E. Green, M. Jenkins, P. Jefferiss, V. Jessamy, J. Madden, K. Munro, N. Myers, S. Naeem, J. Paavola, M. Rayment, S. Rosendo, J. Roughgarden, K. Trumper, and R. K. Turner. 2002. Economic Reasons for Conserving Wild Nature. Science 297:950-953.

Bateman, I. J., E. Coombes, E. Fitzherbert, A. Binner, T. Bad'ura, C. Carbone, B. Fisher, R. Naidoo, and A. R. Watkinson. 2015. Conserving tropical biodiversity via market forces and spatial targeting. Proceedings of the National Academy of Sciences 112:7408-7413.

Black, R. E., S. S. Morris, and J. Bryce. 2003. Where and why are 10 million children dying every year? The Lancet 361:2226-2234.

Carrasco, L. R., T. P. L. Nghiem, T. Sunderland, and L. P. Koh. 2014. Economic valuation of ecosystem services fails to capture biodiversity value of tropical forests. Biological Conservation 178:163-170.

Chan, K. M., A. D. Guerry, P. Balvanera, S. Klain, T. Satterfield, X. Basurto, A. Bostrom, R. Chuenpagdee, R. Gould, and B. S. Halpern. 2012. Where are cultural and social in ecosystem services? A framework for constructive engagement. Bioscience 62:744-756.

Colfer, C. J. P., and H. Soedjito. 1996. Food, forests and fields in a Bornean rain forest: towards appropriate agroforestry development in C. Padoch, and N. L. Peluso, editors. Borneo in transition: people, forests, conservation, and development. CIFOR.

Cowling, R. M., B. Egoh, A. T. Knight, P. J. O'Farrell, B. Reyers, M. Rouget, D. J. Roux, A. Welz, and A. WilhelmRechman. 2008. An operational model for mainstreaming ecosystem services for implementation. Proceedings of the National Academy of Sciences 105:9483-9488.

Dwyer, P. D. 1985. The contribution of non-domesticated animals to the diet of Etolo, southern highlands province, Papua New Guinea. Ecology of Food and Nutrition 17:101-115.

Erskine, W., A. Ximenes, D. Glazebrook, M. da Costa, M. Lopes, L. Spyckerelle, R. Williams, and H. Nesbitt. 2015. The role of wild foods in food security: the example of Timor-Leste. Food Security 7:55-65.

FAO. 1997. Chapter 8 - Malnutrition and micronutrient deficiencies Accessed at: http://www.fao.org/docrep/w0078e/w0078e09.htm. Agriculture food and nutrition for Africa - A resource book for teachers of agriculture. Food and Agricultural Organization of the United Nations, Rome.

Foli, S., J. Reed, J. Clendenning, G. Petrokofsky, C. Padoch, and T. Sunderland. 2014. To what extent does the presence of forests and trees contribute to food production in humid and dry forest landscapes?: a systematic review protocol. Environmental Evidence 3:15.

Forest Trends. 2015. Ecosystem MarketPlace. Marketwatch. Water Markets. Watershed Investment in Asia. Forest Trends. Available at: http://www.ecosystemmarketplace.com/marketwatch/.

Game, E. T., E. Meijaard, D. Sheil, and E. McDonald-Madden. 2014. Conservation in a wicked complex world; challenges and solutions. Conservation Letters 7:271-277.

Guerry, A. D., S. Polasky, J. Lubchenco, R. Chaplin-Kramer, G. C. Daily, R. Griffin, M. Ruckelshaus, I. J. Bateman, A. Duraiappah, T. Elmqvist, M. W. Feldman, C. Folke, J. Hoekstra, P. M. Kareiva, B. L. Keeler, S. Li, E. McKenzie, Z. Ouyang, B. Reyers, T. H. Ricketts, J. Rockström, H. Tallis, and B. Vira. 2015. Natural capital and ecosystem services informing decisions: From promise to practice. Proceedings of the National Academy of Sciences 112:7348-7355.

Howson, P., and S. Kindon. 2015. Analysing access to the local REDD+ benefits of Sungai Lamandau, Central Kalimantan, Indonesia. Asia Pacific Viewpoint 56:96-110.

Ickowitz, A., B. Powell, M. A. Salim, and T. C. Sunderland. 2014. Dietary quality and tree cover in Africa. Global Environmental Change.

International Institute for Applied Systems Analysis. 2014. GAEZ v3.0 Global Agro-ecological Zones. IIASA. Accessed at: http://webarchive.iiasa.ac.at/Research/LUC/GAEZv3.0/.

Laurans, Y., and L. Mermet. 2014. Ecosystem services economic valuation, decision-support system or advocacy? Ecosystem Services 7:98-105. 
Laurans, Y., A. Rankovic, R. Billé, R. Pirard, and L. Mermet. 2013. Use of ecosystem services economic valuation for decision making: Questioning a literature blindspot. Journal of Environmental Management 119:208219.

Leader-Williams, N., W. M. Adams, and R. J. Smith 2010. Trade-offs in conservation: deciding what to save. John Wiley \& Sons.

Lee, J. S. H., Z. Jaafar, A. K. J. Tan, L. R. Carrasco, J. J. Ewing, D. P. Bickford, E. L. Webb, and L. P. Koh. 2016. Toward clearer skies: Challenges in regulating transboundary haze in Southeast Asia. Environmental Science \& Policy 55, Part 1:87-95.

Margono, B. A., P. V. Potapov, S. Turubanova, F. Stolle, and M. C. Hansen. 2014. Primary forest cover loss in Indonesia over 2000-2012. Nature Climate Change.

McCarthy, J., and Z. Zen. 2010. Regulating the Oil Palm Boom: Assessing the Effectiveness of Environmental Governance Approaches to Agro-industrial Pollution in Indonesia. Law \& Policy 32:153-179.

McDermott, M., S. Mahanty, and K. Schreckenberg. 2013. Examining equity: a multidimensional framework for assessing equity in payments for ecosystem services. Environmental Science \& Policy 33:416-427.

Meijaard, E., S. Wunder, M. R. Guariguata, and D. Sheil. 2014. What scope for certifying forest ecosystem services? Ecosystem Services 7:160-166.

Myers, N., R. A. Mittermeier, C. G. Mittermeier, G. A. B. da Fonseca, and J. Kent. 2000. Biodiversity hotspots for conservation priorities. Nature 403:853-858.

Nasi, R., D. Brown, D. Wilkie, E. Bennett, C. Tutin, G. Van Tol, and T. Christophersen. 2008. Conserva-tion and use of wildlife-based resources: the bushmeat crisis. Secretariat of the Convention on Biological Diversity, Montreal. and Center for International Forestry Research (CIFOR), Bogor. Technical Series 50.

Nghiem, T., and L. Carrasco. 2016. Mobile Applications to Link Sustainable Consumption with Impacts on the Environment and Biodiversity. Bioscience:biw016.

Ogle, B. M., P. H. Hung, and H. T. Tuyet. 2001. Significance of wild vegetables in micronutrient intakes of women in Vietnam: an analysis of food variety. Asia Pacific Journal of Clinical Nutrition 10:21-30.

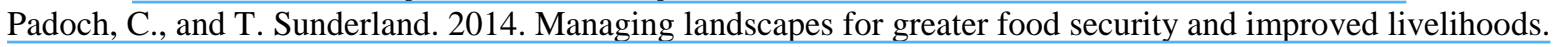
unasylva 64.

Peh, K. S.-H., A. Balmford, R. B. Bradbury, C. Brown, S. H. Butchart, F. M. Hughes, A. Stattersfield, D. H. Thomas, M. Walpole, and J. Bayliss. 2013. TESSA: a toolkit for rapid assessment of ecosystem services at sites of biodiversity conservation importance. Ecosystem Services 5:51-57.

Phelps, J., B. Hariyanti, A. C. Sinaga, and A. Dermawan. 2014. Environmental Valuation in Indonesia: Implication for forest policy, legal liability and state losses estimates. Center for International Forestry Research (CIFOR), Bogor, Indonesia.

Phillips, M., F. Enyuan, F. Gavine, T. Hooi, M. Kutty, N. Lopez, R. Mungkung, T. Ngan, P. White, and K. Yamamoto. 2009. Review of environmental impact assessment and monitoring in aquaculture in AsiaPacific. FAO, Rome(Italy).

Powell, B., S. H. Thilsted, A. Ickowitz, C. Termote, T. Sunderland, and A. Herforth. 2015. Improving diets with wild and cultivated biodiversity from across the landscape. Food Security:1-20.

Renard, D., J. M. Rhemtulla, and E. M. Bennett. 2015. Historical dynamics in ecosystem service bundles. Proceedings of the National Academy of Sciences 112:13411-13416.

Ruckelshaus, M., E. McKenzie, H. Tallis, A. Guerry, G. Daily, P. Kareiva, S. Polasky, T. Ricketts, N. Bhagabati, and S. A. Wood. 2013. Notes from the field: lessons learned from using ecosystem service approaches to inform real-world decisions. Ecological Economics 115:11-21.

Runting, R. K., E. Meijaard, N. K. Abram, J. A. Wells, D. L. A. Gaveau, M. Ancrenaz, H. P. Posssingham, S. A. Wich, F. Ardiansyah, M. T. Gumal, L. N. Ambu, and K. A. Wilson. 2015. Alternative futures for Borneo show the value of integrating economic and conservation targets across borders. Nat Commun 6.

Sayer, J., T. Sunderland, J. Ghazoul, J.-L. Pfund, D. Sheil, E. Meijaard, M. Venter, A. Boedhihartono, M. Day, C. Garcia, C. van Oosten, and L. Buck. 2013. Ten principles for a landscape approach to reconciling agriculture, conservation, and other competing land uses. Proc Natl Acad Sci 110:8349 - 8356.

Schlegel, S. A., and H. A. Guthrie. 1973. Diet and the Tiruray shift from swidden to plow farming. Ecology of Food and Nutrition 2:181-191.

Sodhi, N., L. Koh, B. Brook, and P. Ng. 2004. Southeast Asian biodiversity: an impending disaster. Trends in Ecology \& Evolution 19:654-714.

Stiglitz, J. E., A. Sen, and J.-P. Fitoussi. 2010. Report by the commission on the measurement of economic performance and social progress. Paris: Commission on the Measurement of Economic Performance and Social Progress. 
Sunderland, T., C. Ehringhaus, and B. Campbell. 2008. Conservation and development in tropical forest landscapes: a time to face the trade-offs? Environmental Conservation 34.

Sunderland, T., B. Powell, A. Ickowitz, S. Foli, M. Pinedo-Vasquez, R. Nasi, and C. Padoch. 2013. Food security and nutrition: The role of forests. Discussion paper. Center for International Forestry Research (CIFOR), Bogor, Indonesia.

Tilman, D., and M. Clark. 2014. Global diets link environmental sustainability and human health. Nature 515:518522.

To, P. X., W. H. Dressler, S. Mahanty, T. T. Pham, and C. Zingerli. 2012. The Prospects for Payment for Ecosystem Services (PES) in Vietnam: A Look at Three Payment Schemes. Human Ecology 40:237-249.

\section{Tables and figures}

Table 1. Five challenges for the reconciliation of agricultural production and forest ES in Southeast Asia.

\begin{tabular}{ll}
\hline Challenge & Description \\
\hline 1 & $\begin{array}{l}\text { Scarcity of easy to use on-the-ground tools for rapid ES valuation. } \\
\text { Poor understanding and quantification of forest ES benefits with regards to food } \\
\text { security and well-being. }\end{array}$ \\
& $\begin{array}{l}\text { Weak demand for ES by economic activities and weak political will to integrate and } \\
\text { enforce ES into regulatory frameworks. }\end{array}$ \\
& $\begin{array}{l}\text { Poor engagement of environmental economists and ES valuation with policy } \\
\text { makers. }\end{array}$ \\
& $\begin{array}{l}\text { Lack of transparent discussion platforms with which stakeholders can reach } \\
\text { consensus on competing land uses to avoid power plays and corruption. }\end{array}$ \\
\hline
\end{tabular}

Table 2. Research priorities to overcome the five challenges to reconcile agricultural production and forest ES in Southeast Asia.

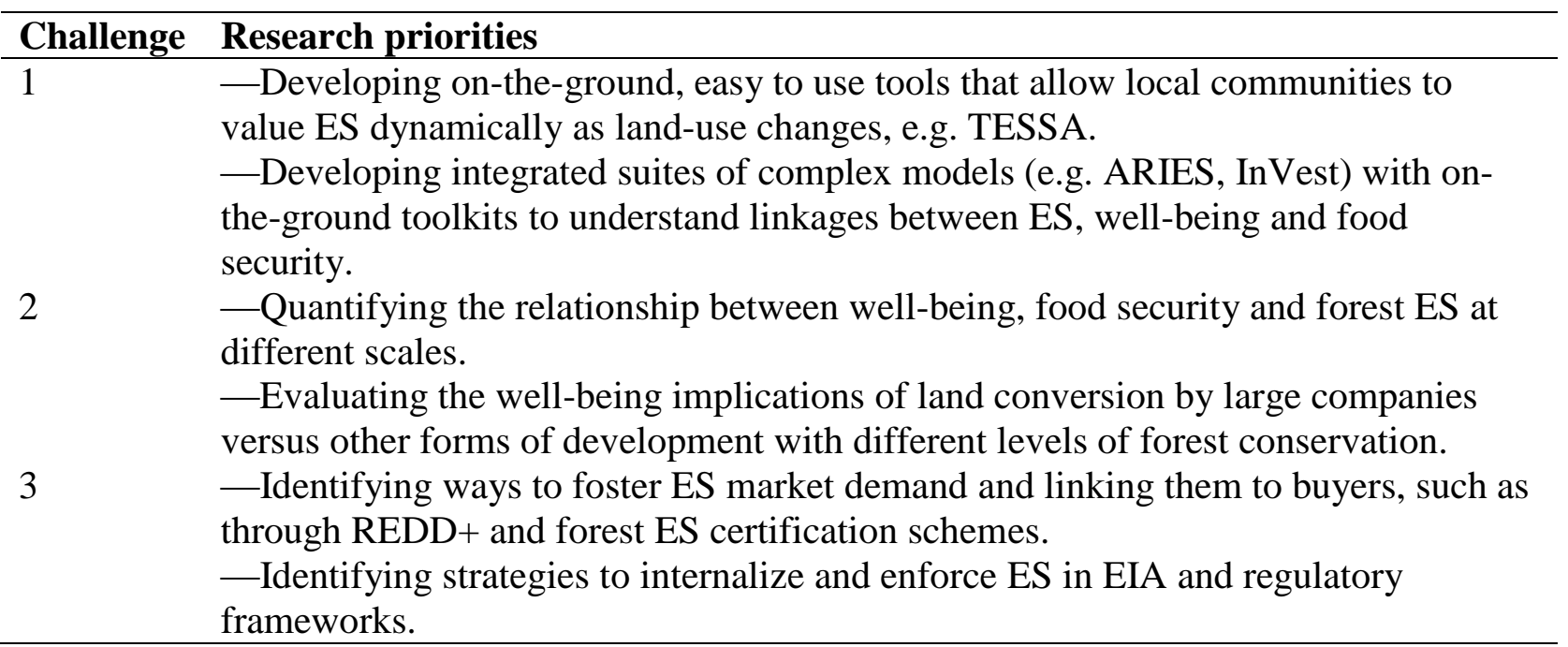



$4 \quad$ - Identifying factors that hinder the engagement of the ES valuation process with policy makers and stakeholders.
-Analysis of the cognitive and institutional dynamics of policy makers and institutions and how these hinder the implementation of ES into policy.
5 - Identifying the barriers that prevent discussion platforms and the engagement of all stakeholders.
- Identifying the most effective ways to counter and reduce corruption and power plays in consensus platforms.

Fig. 1. Spatial conflicts between agricultural production and forest ES in Southeast Asia. A: ES economic value of tropical forests based on a spatial regression meta-analysis (Carrasco et al. 2014) and biodiversity hotspots in Southeast Asia (Myers et al. 2000). B: distribution of oil palm yield potential, one of the main cash crops in the region (International Institute for Applied 499 Systems Analysis 2014).
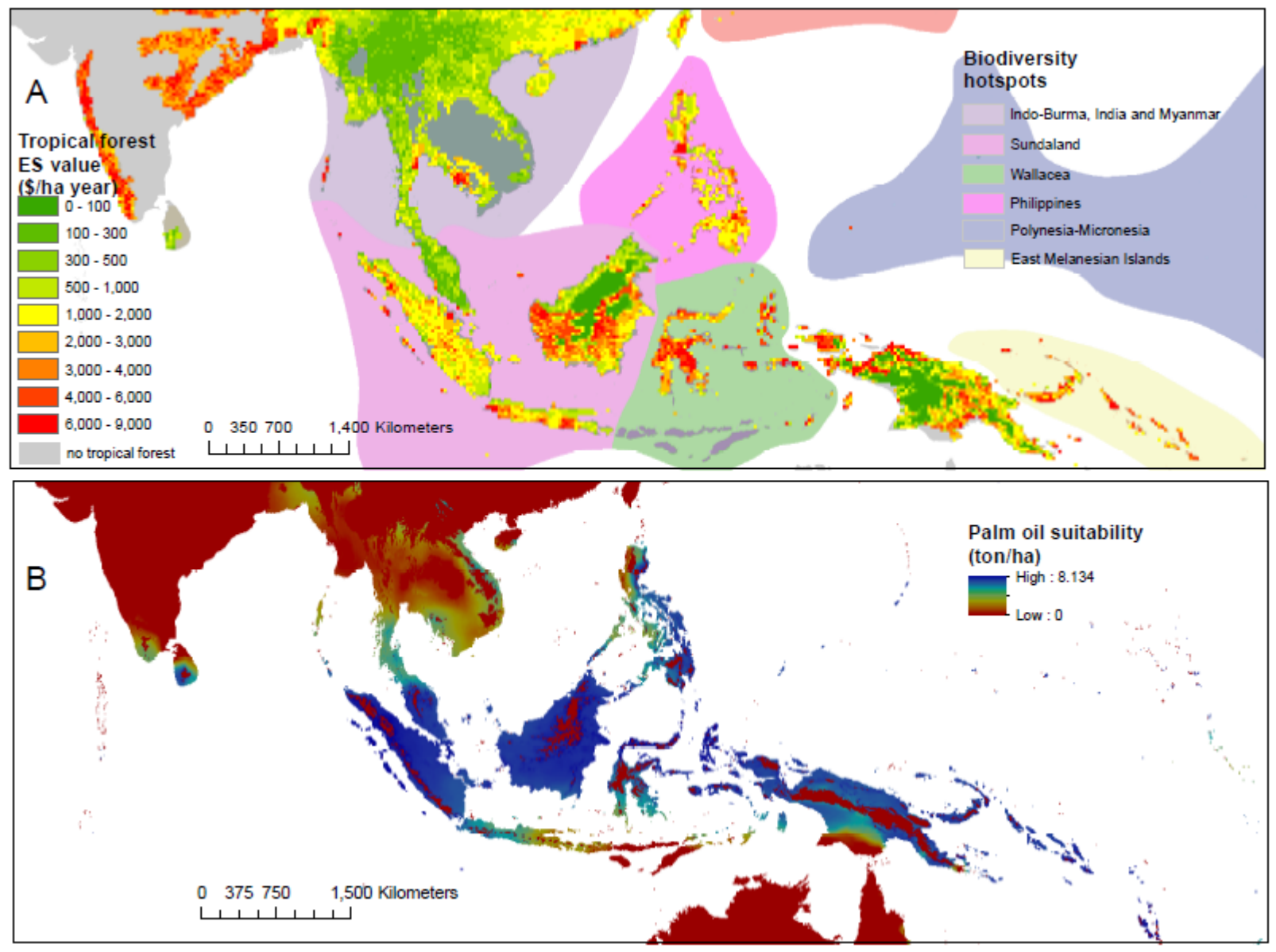
Fig. 2. Conceptual framework for the reconciliation of tropical forest ES and agricultural production through the internalization of forest ES values. The top panel describes the land-use system where deforestation drivers arising from the demand of agricultural products pose a landuse decision-making problem in Southeast Asia. The bottom panel describes the process to internalize ES into land-use planning. The necessary processes for internalization of ES are: quantifying the value of forest ES that is not captured by markets; understand the links between forest ES, food security and well-being; and sufficient demand for ES (markets and certification schemes) and political will to integrate them into regulatory frameworks. Once these processes are in place, the engagement of ES valuation with policy makers (that feeds back into political will and demand for ES) and the development of consensus building platforms for all

stakeholders are needed to reconcile the trade-offs between competing land uses.

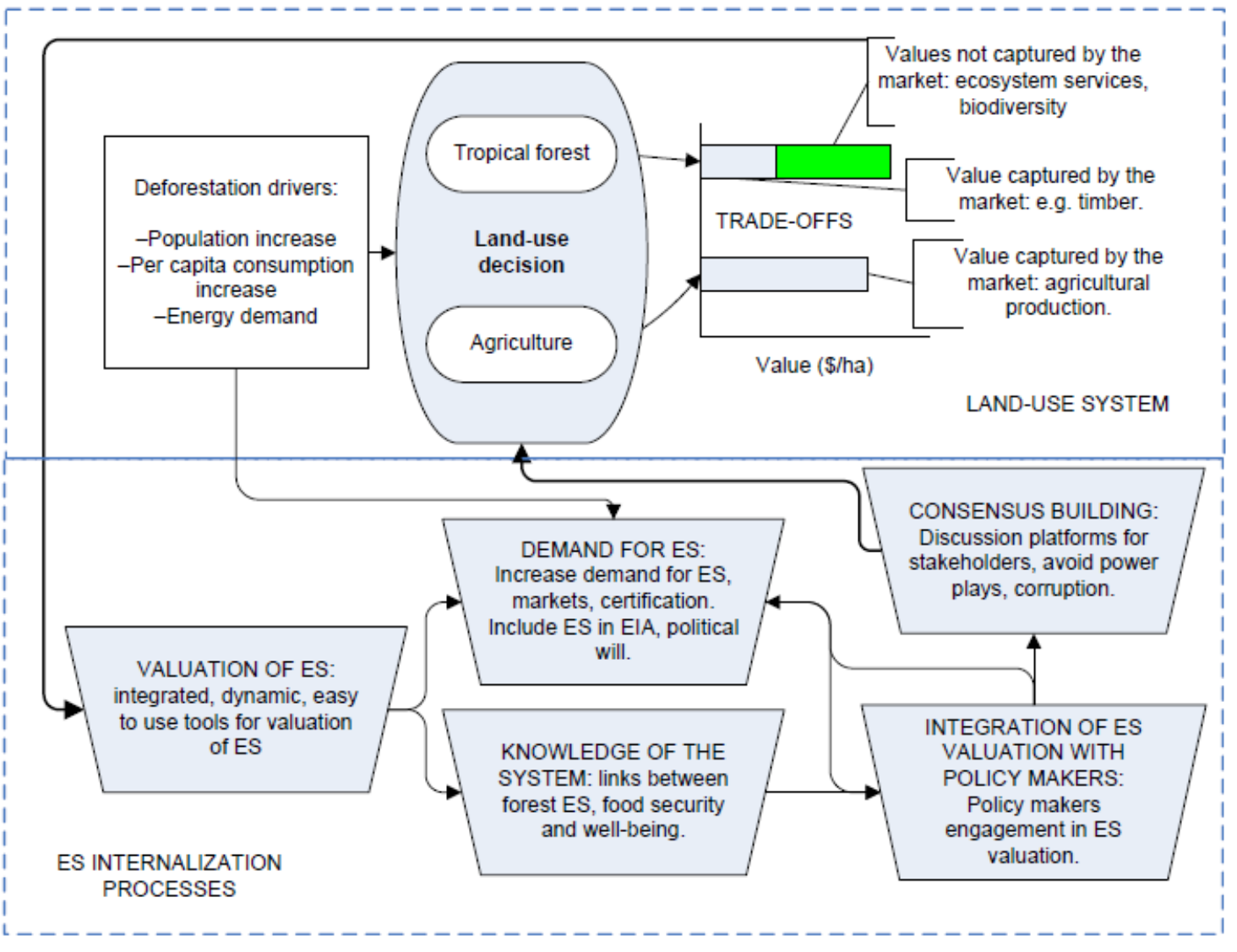

